\title{
Physical characteristics of the Antarctic sea-ice zone derived from modelling and observations
}

\author{
W. F. Budd, ${ }^{1}$ XINGREN WU, $^{1,2}$ P. A. ReID \\ 'Antartic CRC, GPO Box 252-80, Hobart, Tasmania 7001, Australia \\ ${ }^{2}$ Australian Antarctic Division, GPO Box 252-80, Hobart, Tasmania 7001, Australia
}

\begin{abstract}
Antarctic sea ice plays a key role in the present climate system, providing a regulating balance between the atmosphere and ocean heat fluxes, as well as influencing the salt fluxes and deep water formation over the continental shelves. The severe winter environmental conditions of the Antarctic sea-ice zone make it difficult to observe many of the physical characteristics in a comprehensive way. The inter-relations between the variables mean that much can be learnt from the observations of some features along with detailed numerical modelling of the whole system and the interactions between the variables. This study therefore aims to use numerical modelling of the atmosphere, sea ice and surface mixed-layer ocean in the sea-ice zone, together with observations to simulate a comprehensive range of parameters and their variability through the annual cycle to provide a basis for further observations and model validation for the present climate.

The model includes a coupled atmospheric general circulation model with an interactive dynamic and thermodynamic sea-ice model and surface mixed-layer ocean. The deep ocean and ocean surface conditions outside the sea-ice zone are constrained to the present mean climate conditions to ensure no climatic drift. The sea-ice model is similar to previous published versions, but has refined schemes for partitioning of the freezing of frazil ice within the leads and under the ice floes, and for rafting. These perform well in both polar regions with the same physics. The model simulates the annual cycle of atmospheric and sea-ice features well in comparison with data from the global atmospheric analyses, the satellite sensing of sea ice, and the limited in situ surface observations.

The output from the model also includes: all components of the heat fluxes, atmospheric profiles and surface temperatures for air, ice and ice-ocean mixtures, open-water fractions, surface snow and snow-ice depths, and the sea-ice convergence divergence and drift. The comparison of these features with additional observations provides a means for further validating the model and representing the present climate more closely.
\end{abstract}

\section{BACKGROUND}

Many of the most important properties of Antarctic sea ice are difficult to measure, particularly through the complete annual cycle and over the entire sea-ice zone. Some features, such as ice concentration, can be observed to some extent in this comprehensive way via satellite, but many features, such as ice thickness, have only been observed by limited sampling from ships or short-term field programs on the pack ice. The objective of the present modelling study is to provide a comprehensive, self-consistent set of derived features of the sea-ice region, through the annual cycle from a coupled atmosphere sea-ice model by matching the model results to the observations available as well as possible. This allows the observations of those features that are most readily observed to be used to refine the model parameters and narrow the uncertainties of the less-well-known features that may be more difficult to observe directly.

A large number of model runs have been carried out to obtain reasonable simulations of many of the present features of the sea-ice region in comparison with the stilllimited observational data available. Such features include ice extent (the total sea-ice and water area within the outer sea-ice boundary of $<15 \%$ ice concentration), the sea-ice area and open-water fraction (cf. Fig. 1), the sea-ice thick- ness distribution (cf. Fig. 2), the depth of snow on the surface and the ice movement. Some of the most important features that are not well known include the oceanic heat flux just

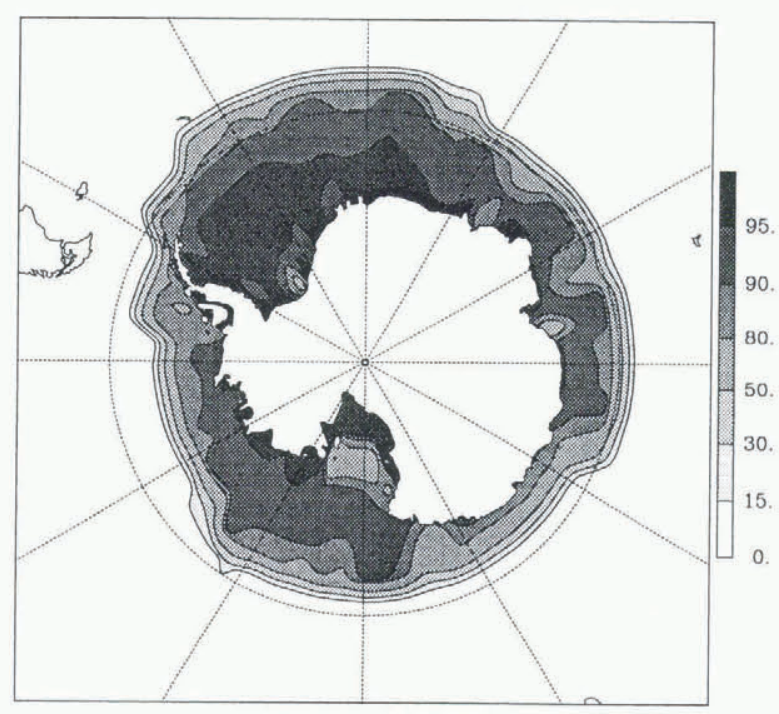

Fig. 1. The mean sea-ice concentration from the model for the period of maximum extent (near September). Contours are in $15,30,50,80,90$ and $95 \%$. 


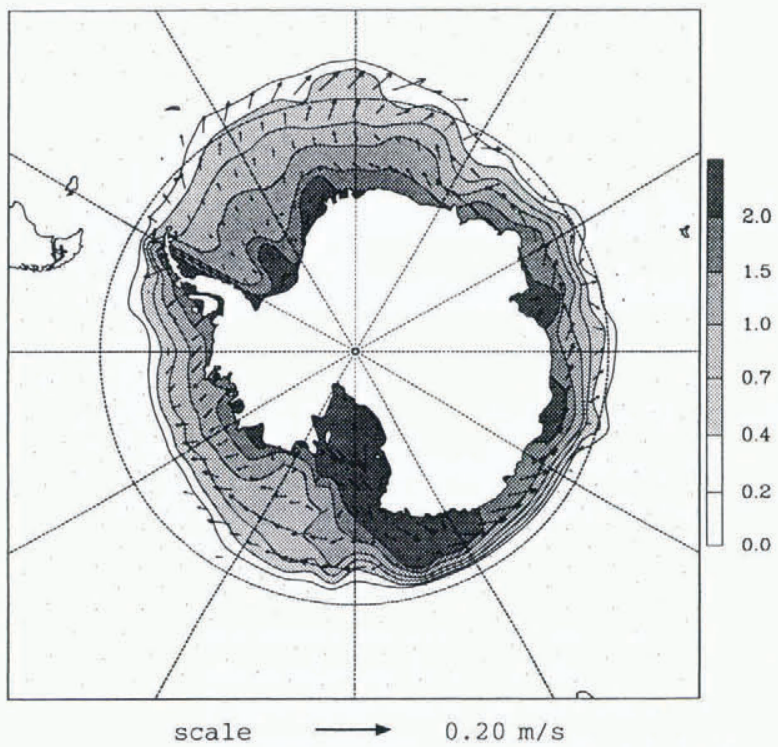

Fig. 2. The monthly mean sea-ice drift from the model is shown superimposed on the corresponding thickness field for the period of maximum ice extent. Ice-thickness contours are $0.2,0.4,0.7,1.0,1.5$ and $2.0 \mathrm{~m}$.

below the sea ice, and the distribution of ice freezing within the open-water leads area relative to the freezing at the base of the sea ice. Large numbers of sensitivity studies have been carried out to determine the "best fit" values of the more uncertain parameters. The model results obtained from using the best-fit parameters giving the closest matching to the observed features have then been used to derive a comprehensive range of other features from the model that are consistent in closures for mass, heat and salt, and that can be used for further comparisons with observations.

The advantages of using a prescribed surface ocean mixed layer for this study, rather than a fully dynamic ocean model, are that the ocean heat and water fluxes can be diagnosed from prescribed temperatures, salinities and ocean currents, based on observations combined with the computed surface fluxes from the model.

The aim of this paper is to summarise work in progress by Budd and associates, on derived physical characteristics of the Antarctic sea ice zone, that illustrates a wide range of the features and their variation through the annual cycle. Examples are given of the comprehensive output available, including plan maps, meridional sections, seasonal cycles, vertical profiles through ocean-ice-atmosphere, and net budget closure summaries. Highlights presented here include the numerical values and relative magnitudes of the various individual features of the sea ice and the heat and fresh-water fluxes through the year (as given in Table 1), the dependence of mean ice thickness on oceanic heat flux (in Table 2), the "self regulating" nature of the freezing and ice concentration through the feedback with sensible heat flux (in Table 3), and the variations of the dominant terms in the seasonal cycle of the heat and water fluxes (in Figs 6 and 7 , to be discussed later). Complete results for the model vari-

Table 1. Values from the model, averaged over the sea-ice extent, for a selection of parameters involved in the heat and water balances at different times of the year and for the annual means, over the areas of maximum and minimum ice extent. The * indicates values averaged over the ice-covered fraction only.

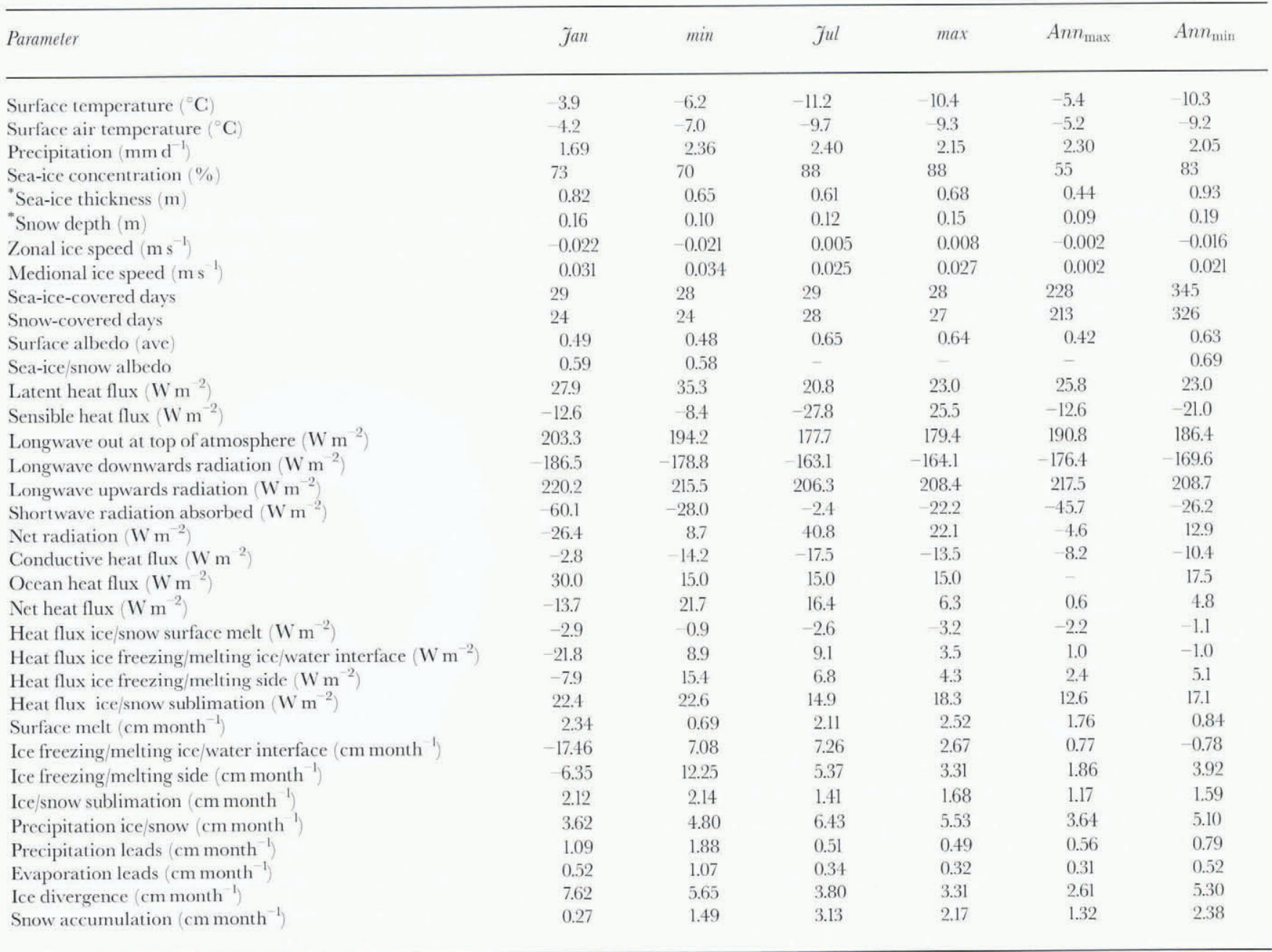


ables are available in electronic form from the authors and a user-ready version is being made accessible via the World Wide Web site of the Antarctic CRC.

Table 2. Average Antarctic sea-ice thickness at maximum iceextent dependence on mean oceanic heal flux

\begin{tabular}{lllllll}
\hline Ocean heat flux $\left(\mathrm{Wm}^{-2}\right)$ & 0 & 5 & 10 & 15 & 25 & 35 \\
Mean thickness $(\mathrm{m})$ & 1.5 & 1.2 & 0.8 & 0.6 & 0.35 & 0.25
\end{tabular}

\section{ATMOSPHERE-SEA-ICE MODEL}

The model used here is based on the scheme outlined by Budd and others (1991) whereby an atmospheric general circulation model (AGCM) is coupled to a dynamic-thermodynamic sea-ice model with a prescribed diagnostic ocean mixed-layer model. The atmospheric model is a spectral 21 (rhomboidal) wave number version with nine vertical sigma levels (pressure levels relative to the surface pressure), and has been described by Simmonds (1985). Modifications of the model to treat subgrid-scale sea ice and open water by separate and mixed heat-balance calculations have been described by Simmonds and Budd (1990, 1991). For this study, to preserve the climatology as closely as practicable to the present climate, the sea-surface temperatures (SSTs) outside the sea-ice region have been prescribed as their present seasonally varying climatological mean values, except for ocean points adjacent to the sea ice where heat-balance calculations, with a prescribed mixed-layer depth, determine whether or not ice forms or remains, as well as the ice fraction in the outermost gridcell. A prescribed seasonal climatological cloud distribution is also used to ensure a close match to observed radiation balances.

The coupled sea-ice model used, which is also run at R21 resolution, has been described in general terms by Budd and others (1991) and in detail by Wu (1993) and Wu and others (1997). In general the model is similar to the cavitating fluid version of Flato and Hibler (1990) with only the compressive stresses effective in the sea ice. In particular, in the present model, for low ice concentrations, the sea ice moves in free drift from wind forcing (at $2 \%$ of the wind speed and $25^{\circ}$ to the left in the Southern Hemisphere) until the ice concentration fraction $\left(f_{\mathrm{i}}\right)$ reaches a critical value $\left(f_{\mathrm{i}}=f_{\text {cri }}\right)$, at which stage the ice floes interact and further compaction is progressively resisted by increasing thickness through rafting and ridging. At a maximum ice concentration $\left(f_{\mathrm{i}}=f_{\max }\right)$, increasing thickness retards the compression and conserves ice volume. For the results presented here the parameters have been set at $f_{\text {cri }}=90 \%$ and $f_{\max }=98 \%$, for the Southern Hemisphere.

Another novel feature of the model is the partitioning scheme for the two fractional parts of the total ice that freeze in the water column of the leads, and that then accumulate either on the base or on the sides of the ice floes. In brief this depends on the open-water fraction $\left(f_{\mathrm{w}}\right)$ and the ice thickness $\left(h_{\mathrm{i}}\right)$. The physical principles involved in this scheme are based on the observations that the frazil ice formed from freezing in leads is distributed over some depth in the water column, but with concentration decreasing with depth. The relative ocean currents move the frazil ice crystals horizontally as they settle upwards, giving a fraction of the total ice accumulating in the leads dependent on the open-water fraction and the ice thickness. It is also assumed that the ice accumulating in the leads accrues on the sides of the floes. The following relation has been found to represent this process in a reasonable way. The portion $\left(E_{\mathrm{s}}\right)$ of the total heat $\left(Q_{\mathrm{n}}\right)$ for freezing (or melting) that goes to the sides is given by:

$$
E_{\mathrm{s}}=Q_{\mathrm{n}}\left(f_{\mathrm{w}}+\frac{f_{\mathrm{i}} \gamma}{1+\gamma}\right)
$$

where $\gamma=h_{\mathrm{i}} / h_{\mathrm{c}}$ and $h_{\mathrm{c}}$ is a prescribed critical ice thickness.

The corresponding portion for the base is:

$$
E_{\mathrm{b}}=Q_{\mathrm{n}}\left(\frac{f_{\mathrm{i}}}{1+\gamma}\right) \text {. }
$$

Sensitivity studies have been carried out for $h_{\mathrm{c}}$ in the range of $0.05-1 \mathrm{~m}$, and the results presented here are with $h_{\mathrm{c}}=1 \mathrm{~m}$. Other features in the coupled atmosphere seaice model described by Wu and others (1997) include prognostic precipitation, evaporation and snow depth. A scheme for "white ice" treats the formation of ice from snow when it is flooded by sea water. A prognostic scheme for sea-ice and snow albedo depends on ice thickness, snow depth and temperature.

\section{SERIES OF SIMULATIONS}

The coupled atmosphere-sea-ice model was run globally over a series of annual cycle simulations to test the sensitivities of the model sea ice to the major uncertainties in the various parameterisations (e.g. oceanic heat flux, partitioning fractions for the leads and basal freezing, the sea-ice albedo, the ocean mixed-layer depth and the rafting and ridging scheme). Some runs of six annual cycles were obtained, but it was generally found that after spinning up for one year, two years of repeatable annual cycles were suf-

\begin{tabular}{|c|c|c|c|c|c|c|c|}
\hline \multirow[b]{2}{*}{ Ice concentration $C_{\mathrm{i}}(\%)$} & \multicolumn{6}{|c|}{ Prescribed } & \multirow{2}{*}{$\begin{array}{c}\text { Interactive } \\
83\end{array}$} \\
\hline & 100 & 95 & 80 & 50 & 20 & 0 & \\
\hline \multicolumn{8}{|l|}{ Surface temperature $(\mathrm{C})$} \\
\hline Sea ice & -19.1 & 17.9 & -15.5 & -11.4 & -8.5 & - & -11.9 \\
\hline Ice + leads & -19.1 & -17.1 & -12.8 & -6.6 & -3.1 & -1.8 & -10.2 \\
\hline Air & -16.6 & -15.4 & -12.7 & -9.0 & -6.5 & -5.5 & -10.3 \\
\hline $\boldsymbol{\Delta}\left(\mathbf{T}_{\mathrm{s}}-\mathbf{T}_{\mathrm{a}}\right)^{\circ} \mathrm{C}$ & -2.5 & -1.7 & -0.1 & +2.4 & +3.4 & +3.9 & +0.1 \\
\hline Sensible heat $\left(\mathrm{W} \mathrm{m}^{-2}\right)$ & -46.2 & -34.1 & -6.3 & +29.4 & +48.5 & +56.7 & -17.0 \\
\hline Latent heat $\left(\mathrm{W} \mathrm{m}^{2}\right)$ & +20.3 & +24.1 & +31.8 & +43.1 & +49.2 & +48.3 & +29.6 \\
\hline Turbulent (sensible and latent heat) $\left(\mathrm{W} \mathrm{m}^{-2}\right)$ & -25.9 & -10.0 & +25.5 & +72.5 & +97.7 & +105.0 & +12.6 \\
\hline
\end{tabular}

Table 3. Ice concentration, surface temperatures and turbulent heat fluxes 
ficient to establish a new seasonal climatology, and produce clear differences from the 6 years of control results.

It was found that reasonable matches could be obtained of the limited atmosphere, ice and surface-ocean observations available for the major sea-ice-zone features. Some of these are illustrated in more detail in $\mathrm{Wu}$ and others (1997). Here we note some of the compilations from observations of major sea-ice features as follows: ice thickness from Budd (1982, 1986), Allison and others (1993) Worby and others (1994), Allison and Worby (1994); ice extent and concentration from Zwally and others (1983), Gloersen and others (1992), also Allison and others (1993) and Worby and others (1996); albedo from Allison and others (1993) and ice drift from Budd (1986), Allison (1989), Martinson and Wamser (1990) and Kottmeier and others (1992).

The most important unknown feature was the prescribed oceanic heat flux, which was found to have a bestfit annual average over the sea-ice-covered extent of about $10-15 \mathrm{Wm}^{2}$, with slightly higher values in summer than in winter. The higher oceanic heat flux in summer is accompanied by higher radiation absorption in the ocean and net melting of the sea ice.

The variation of mean ice thickness (at the time of maximum ice extent) with the magnitude of the prescribed oceanic heat flux, from the series of annual cycle simulations, for sensitivity tests, is summarised in Table 2.

Further runs were carried out with the sea-ice concentration prescribed as the seasonally varying mean values taken from Zwally and others (1983). The results from these runs in general differed only slightly from the best-fit interactive runs. However some features, such as the heat flux, freezing and ice dynamics, can differ significantly between interactive and prescribed conditions, as shown by $\mathrm{Wu}$ and others (1996). The best-fit interactive runs were used to derive a comprehensive set of features for the sea-ice region as indicated below.

\section{SUMMARY OF KEY GHARACTERISTICS}

Table 1 summarises the major components of the heat, mass and fresh-water budgets. Values are given for the averages over the sea-ice zone (i.e. the sea-ice and ocean area inside of the maximum sea-ice extent), for the annual mean, the near-solstice periods (January and July) and near the maximum and minimum sea-ice extent. These allow the primary features of the annual cycle to be discerned. This seasonal variation is further illustrated by Figure 3, which shows the annual cycles of extent and area, and Figures 4 and 5, which show examples of some features in the zonal mean varying with latitude through the annual cycle. In particular the latent heat flux from the total freezing or melting is shown in Figure 4a, and the total surface freshwater flux which, besides freezing and melting, includes precipitation minus evaporation $(P-E)$ and the effects of ice movement, is shown in Figure 5a. These figures also show the seasonal cycles of the area averages over the different ocean regions defined by Zwally and others (1983) as well as for the total Southern Ocean sea-ice zone. Net balance closures for heat, mass, fresh water and salt can be carried out over the upper and lower ice (or snow) surfaces, the ice and snow column total, the open-water surface and the average over a gridbox, with weighting for the ice concentration and open-water fractions.

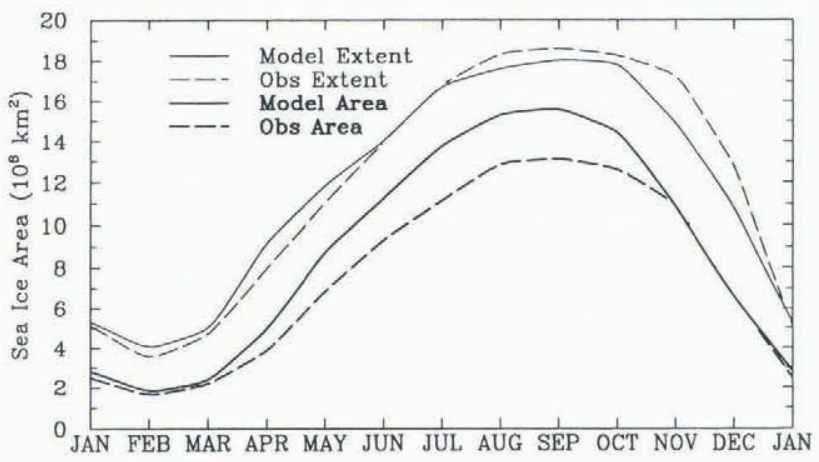

Fig. 3. Seasonal cycle of simulated (solid lines) and derived from satellite (SSM/I), (dashed lines) monthly averaged sea-ice extent (the ice and leads area to the ice edge - thin lines) and ice area (ice fraction only - bold lines) in units $10^{6} \mathrm{~km}^{2}$. Surface observations in winter indicate the satellitederived concentrations and ice area may be too low.
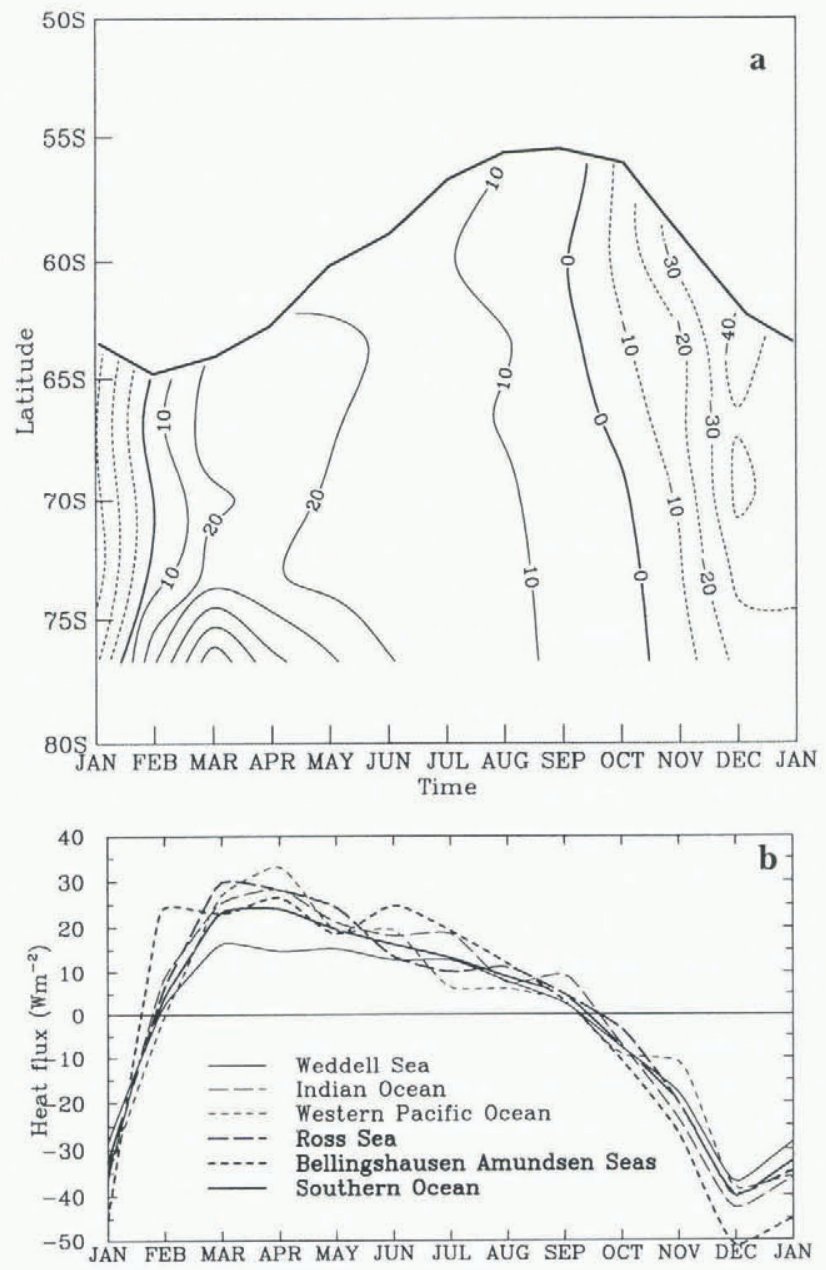

Fig. 4. Seasonal cycle of ( a) zonally averaged and ( $b$ ) areaweighted averaged latent heat flux from total freezing/melting $\left(Q_{\mathrm{fom}}=Q_{\mathrm{m}}^{\mathrm{sfc}}+Q_{\mathrm{fom}}^{\mathrm{bas}}+Q_{\mathrm{fom}}^{\mathrm{ltb}}+Q_{\mathrm{fom}}^{\mathrm{lts}}\right)$ in the Southern Hemisphere sea-ice covered zone. The contour intervals are $10 \mathrm{~W} \mathrm{~m}^{-2}$. Positive values correspond to sea-ice freezing.

Examples of balance closures can be seen in Table 4 .

The variation through the year of the major components in the heat and fresh-water balances over the sea-ice zone are shown in Figures 6 and 7 respectively. The averages are computed in two ways: firstly over the fixed region of maximum sea-ice extent; and secondly over the instantaneous sea-ice extent as it varies in area through the year. 

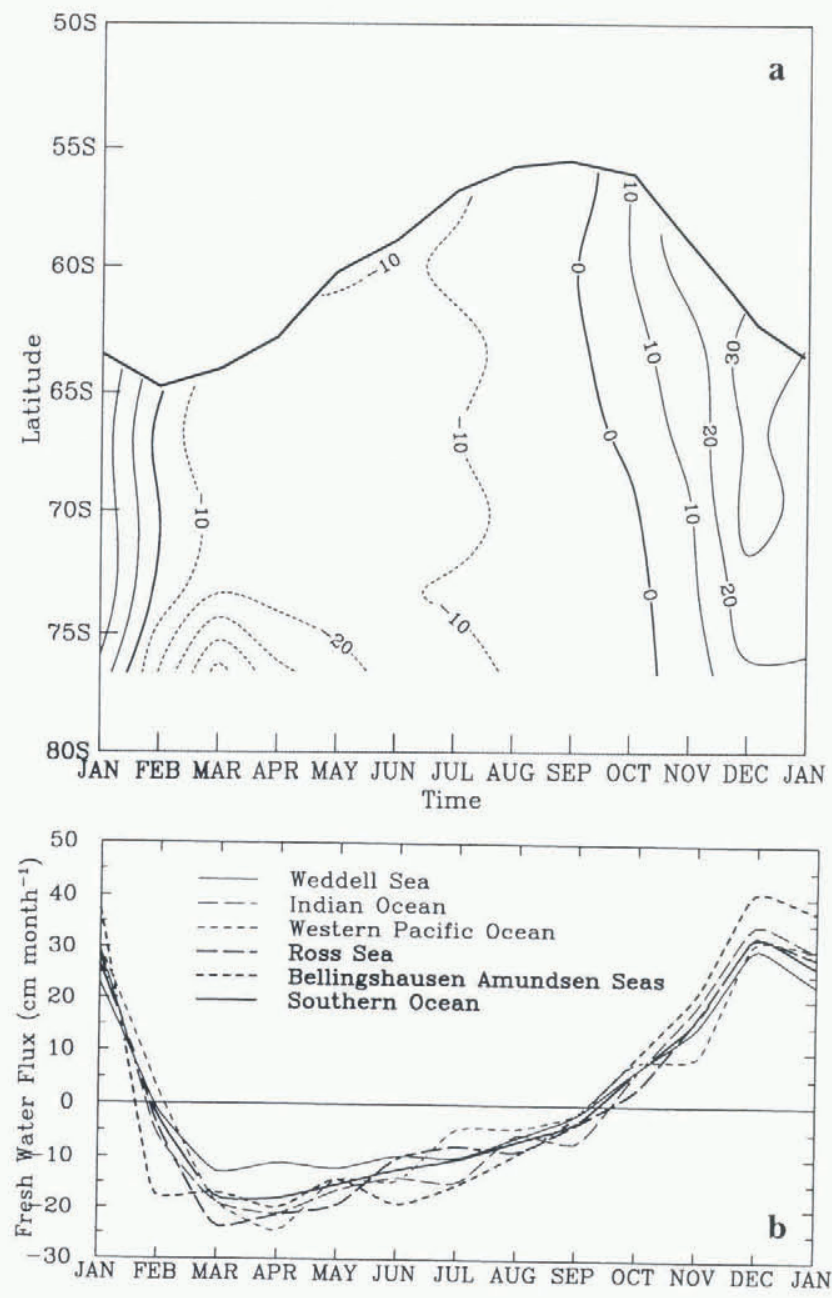

Fig. 5. Seasonal cycle of $(a)$ zonally averaged and (b) areaweighted averaged net fresh-water balance for the water column $(\partial F W / \partial t)$ in the Southern Hemisphere sea-ice-covered zone. The conlour intervals are $10 \mathrm{~cm} \mathrm{month}^{\prime}$ (water equivalent).

\section{DISCUSSION OF RESULTS}

\section{Ice concentration and thickness}

The distribution of ice concentration at the time of maximum sea-ice extent is shown in Figure 1. This compares reasonably well with the observations from satellite as derived by Gloersen and others (1992) but the model results tend to be higher near the coast. The annual cycle of ice extent and area is shown together with that from the SSMI satellite data in Figure 3. The model ice areas and concentrations tend to be higher than the satellite-derived areas throughout the winter. However the direct surface observations carried out in the winter of 1995 by Worby and others (1996) obtained even higher concentrations. These and other similar results raise questions concerning the algorithms that have been used to derive the ice concentrations from the satellite radiances, insofar as the extensive areas of thin, dark ice may be missed.

The ice-thickness distribution, near maximum extent, is shown (along with the mean ice drift) in Figure 2, and it also appears reasonable in comparison with the limited observational data available e.g. Budd (1991), Allison and Worby (1994), Worby and others (1994).

It is found that the ice thickness in the model is very sensitive to the prescribed oceanic heat flux, whereas the ice concentration is much less dependent. A similar result was also found for the Arctic. The dependence of the maximum average sea-ice thickness over the Antarctic sea-ice zone on the magnitude of the prescribed constant oceanic heat flux is shown in Table 2. The observations support a mean thickness near maximum ice extent of about $0.6-0.8 \mathrm{~m}$, which indicates that an annual average oceanic heat flux over the area in the range of $10-15 \mathrm{~W} \mathrm{~m}^{-2}$ is most appropriate. It is important to note that the model calculations are carried out over fixed geographical grid areas and include the effects of the continual motion of the ice. The mean movement of the ice at the time of maximum extent, as illustrated in Figure 2, agrees reasonably well with the mean drift rates derived from buoys (cf. Budd (1986, 1991), Allison (1989), Kottmeier and others (1992).

\section{Summary of major variables}

Table 1 gives a selection of the values of many of the key variables averaged over the sea-ice zone for the annual mean, and at times of the year of particular interest to indicate the seasonal changes (January, minimum extent (February to March), July, and maximum extent (September to October)). Annual averages are also shown computed over the fixed areas of maximum ice extent $\left(A n n_{\max }\right)$ and minimum ice extent $\left(A n n_{\min }\right)$. These results clearly show the relative magnitudes of the various terms in the heat and water balances and how they vary through the year. Note that the region of the $A n n_{\max }$ extends further north, so that the average ice thickness is less, and the average temperature higher, than for the $A n n_{\min }$ region.

In general, the parameters are computed as equivalent weighted averages over the total sea-ice and leads area, except as marked by the * (such as ice thickness), where the values apply to the ice-covered fraction only. The values

Table 4. Examples of balance closures included (at the surface)

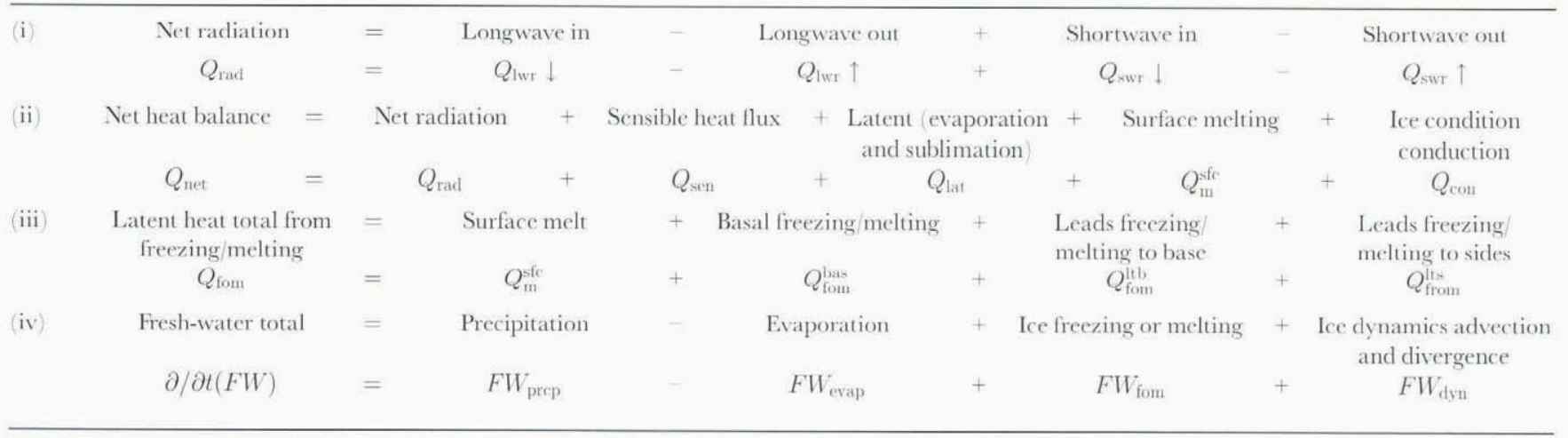


are monthly averages over the sea-ice and leads region for January, the minimum ice extent (min) about March, for July, and for the time of maximum ice extent ( $\max$ ), about September. The annual averages are calculated over the fixed regions of maximum ice extent $\left(A n n_{\max }\right)$ and the region of minimum ice extent $\left(A n n_{\min }\right)$.

The snow depths and precipitation correspond to a mean density of $0.33 \mathrm{Mg} \mathrm{m}^{-3}$. The signs of the heat fluxes are taken as positive upwards except for the ice conductive heat flux, which is negative upwards (towards the ice surface). Within the pack-ice zone it has been assumed that the sea water remains at freezing point while ice is present. This means that the sea-ice-surface temperature and the ice concentration determine the average surface temperature, through a weighted mean.

The largest terms in the heat balance are the inwardand outward-radiation terms, and the greatest variability and uncertainties are associated with cloud cover. These terms can be assessed by satellite data for outward shortwave and longwave radiation. The net surface radiation, shortwave absorbed and longwave emitted are strongly dependent on the sea ice, particularly the concentration, and open-water fraction.

\section{Summary of heat-balance components}

Figure 6 shows the annual cycle of the net radiation, along with the other major components of the heat balance. The turbulent heat flux is the sum of the sensible flux and the latent flux from evaporation and condensation.

During the winter the Antarctic pack ice is relatively much more open than in the Arctic. The high average open-water fraction of $15-20 \%$ is maintained by the active, and largely divergent, ice dynamics and the feedback between the sensible heat, the freezing and the ice concentration. Table 3 shows that the sensible heat and the net turbulent heat fluxes change sign close to the observed range of ice concentrations. This feature of the sea ice resembles a "self-regulating system", with the sea-ice concentration tending towards the observed values under the balance between the net radiation heat loss, and the freezing and net ice divergence, through the feedback of the sensible heat flux. The sensible heat is particularly sensitive to the ice concentration, which in turn has a strong influence on the mean surface temperature and the air-surface temperature difference. This is more clearly illustrated in Table 3 , which shows the surface- and air-temperature dependence on ice concentration in July (from the model), in conjunction with the key heat-flux components. These results are from an extension of the studies by Simmonds and Budd (1991) whereby the sea ice was prescribed at a fixed concentration over the entire sea-ice zone for perpetual July simulations with different values of the given ice concentration. Table 3 shows some results for ice concentrations of $100,95,80,50,20$ and $0 \%$, plus results from an interactive run for July with the coupled atmosphere-sea-ice model for which the mean sea-ice concentration averaged $83 \%$. The table shows that the net radiation and latent heat fluxes change slowly with concentration, but the air-surface temperature difference, the sensible heat flux and the net turbulent heat flux can change sign around the general region of the observed predominant sea-ice concentrations. This gives the basis for the tendency towards the self-regulating system whereby the ice concentration strongly adjusts to give the balance through the feed-
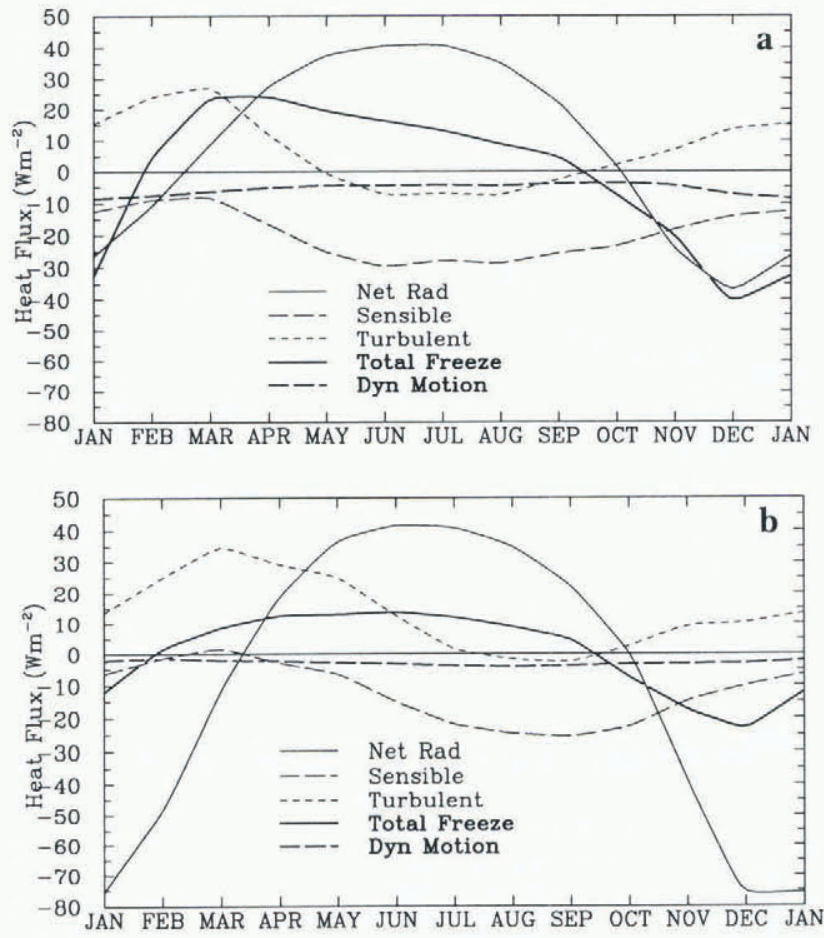

\section{Fig. 6. A summary of the seasonal cycle of some of the major components in the heat balance is shown (a) averaged over the actual sea-ice region as it varies through the year and $(b)$ over the fixed region of maximum sea-ice extent. The net freezing/ melting responds strongly to the net radiative and turbulent forcing, but in turn most strongly influences the ice concentra- tion and sensible heat.}

backs with sensible heat and ice freezing (primarily in the leads) compensating for the thermal heat losses (primarily radiative and latent) and the effects of ice movement (predominantly divergent).

\section{Summary of fresh-water balance components}

Figure 7 summarises the variation through the year of some of the more important terms in the ice and fresh-water balance. The net basal freezing shown includes the contribution from the leads. The precipitation minus evaporation $(P-E)$ only varies slightly through the year, with higher values in winter than summer, and is largely balanced by a net mean northward transport and divergence of the ice from the dynamics. The freezing and melting have relatively large seasonal cycles and only contribute to the net annual mean flux through the net dynamical transport. The total freezing is dominated by the freezing in the leads, and in particular, that part which adds to the sides or the ice area. The relatively substantial amount of freezing in the leads that also accumulates at the base (as is shown in Table 1), together with the effects of rafting, indicates that ice cores can be expected to show relatively large fractions $(\approx 50 \%)$ of frazil ice. This has been born out in observations (e.g. see Allison and others (1993)). The large amount of freezing in the leads is also a factor in the large fraction of young thin ice with relatively small snow depths in comparison with relatively high precipitation rates of around $600 \mathrm{~mm} \mathrm{a}^{-1}$. Many features, such as ice-thickness distributions, snowdepth distributions, sea-ice-surface temperature, ice movement and divergence, can be observed and compared with model output. The results obtained from the 1995 winter 

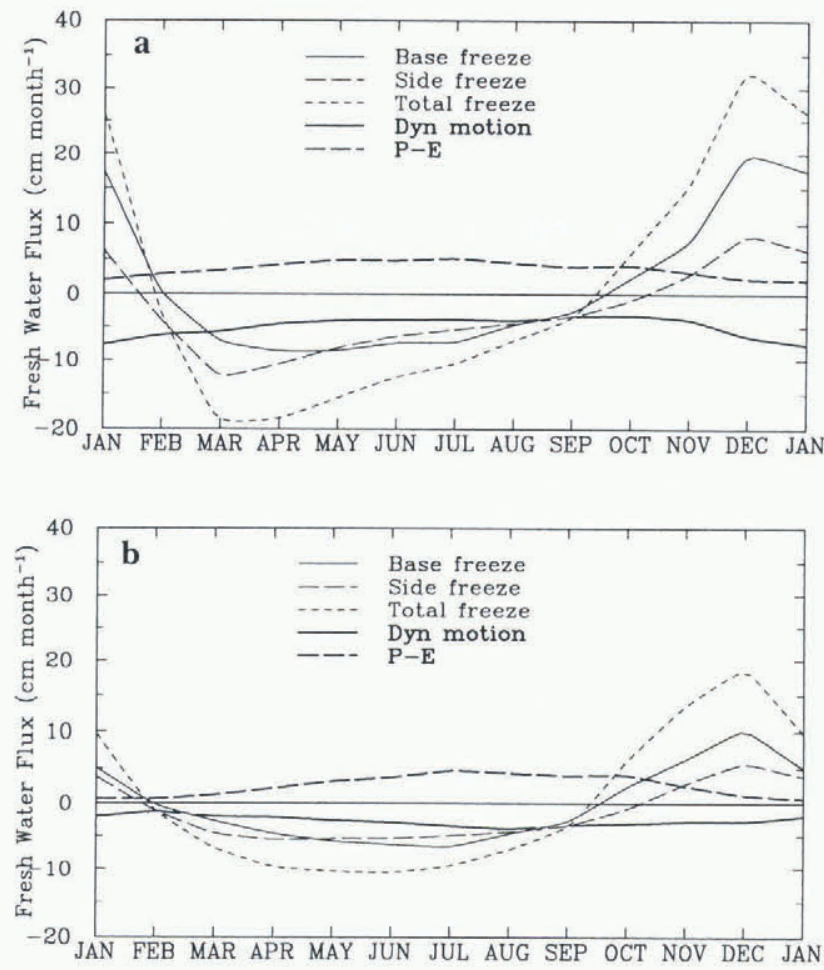

\section{Fig. 7. A summary of the seasonal cycle of major components in the tolal fresh-water balance is shown (a) averaged over the actual sea-ice region as it varies through the year and $(b)$ over the fixed region of maximum sea-ice extent. The ice drift tends to compensate the $(P-E)$ with relatively small seasonal cycle amplitude compared with that of the freezing/melting.}

cruise described by Worby and others (1996) have been particularly valuable and provide encouraging confirmation of the model predictions provided before the voyage.

\section{SUMMARY AND CONCLUSIONS}

In spite of the variability of Antarctic sea ice and the associated meteorological variables over the region, the climatological mean net surface flux components are becoming reasonably well known and constrained to about \pm a few $\mathrm{W} \mathrm{m}{ }^{2}$. More extensive observations of the mean sea-icethickness distribution, and to a lesser extent the ice concentration, can provide the tightest control on net surface fluxes. A comprehensive dataset for the annual cycle of seaice-thickness distribution around the Antarctic would provide the basis for a more accurate estimate of the distribution of the net oceanic heat fluxes.

Sensible heat flux is the most sensitive major heat-flux component to ice concentration and, along with freezing in leads and ice divergence, acts to regulate the concentration towards the observed mean values. Checks on the sensible heat flux can be obtained from comprehensive observations of mean air-minus-surface-temperature differences $\left(T_{\mathrm{a}}-T_{\mathrm{s}}\right)$ along with the other usual meteorological variables such as wind speed. For the fresh-water balance, the excess of precipitation over evaporation is largely balanced by a net northerly transport of snow and ice, and an excess of melting over freezing from the net northerly ice drift. This does not take account of iceberg melt, which is of similar magnitude over the area and needs to be included in coupled models.

The comprehensive range of output available from the model provides a wide range of atmosphere, ice and ocean features that can be compared to observations to constrain more tightly the less well-known features. In particular the surface fluxes derived here, to match the observed sea-ice distribution, provide a sound basis to constrain the oceanic surface heat fluxes in fully coupled atmosphere-ocean global climate models and thereby reduce the need for applying the large surface flux corrections that have been used in the coupled models to prevent model climatic drift.

The present model has also been used to derive surface fluxes over the sea-ice zone initialised by the daily analyses from the global forecasting centres. It should be noted however that so far the analysis centres are not yet using real-time observed sea-ice distributions with interactive sea-ice models. The interactive model in these cases needs to be spun-up for a period long enough for adjustment to the computed fluxes. The results obtained here indicate that considerable improvements to the diagnosis of surface fluxes from the daily analyses can be expected when the analysis centres routinely use interactive sea ice in their analysis and forecast models.

\section{REFERENCES}

Allison, I. 1989. Pack-ice drift off East Antarctica and some implications. Ann. Glaciol., 12, 1-8.

Allison, I. and A. Worby. 1994. Seasonal changes of sea-ice characteristics off East Antarctica. Ann. Glaciol., 20, 195-201.

Allison, I., R. E. Brandt and S. G. Warren. 1993. East Antarctic sea ice: albedo, thickness distribution, and snow cover. J. Geophys. Res., 98 ( 77, 12,417-12,429.

Budd, W. F. 1982. The role of Antarctica in Southern Hemisphere weather climate. Aust. Meteorol. Mag., 30 4), 265272.

Budd, W. F. 1986. The Southern Hemisphere circulation of atmosphere, ocean and sea ice. In Second International Conference on Southern Hemisphere Meteorology, December 1-5, 1986.Wellington. New Zealand. Proceedings. Boston. MA, American Meteorological Society, $101-106$.

Budd, W. F. 1991. Antarctica and global change. Climatic Change, 18 2-3), $271-299$.

Budd, W. F., I. Simmonds and X. Wu. 1991. The physical basis for a dynamic Antarctic sea-ice model for use with an atmospheric GCM. Ann. Glaciol., 15, $196-203$.

Flato, G. M. and W. D. Hibler, III. 1990. On a simple sea-ice dynamics model for climate studies. Ann. Glaciol., 14, $72-77$.

Glocrsen, P., W. J. Campbell, D.J. Cavalieri, J. C. Comiso, C. L. Parkinson and H.J. Zwally. 1992. Arctic and Antartic sea ice, 1978 1987: satellite passive-microwave observations and analysis. Washington, DC, National Acronautics and Space Administration. (NASA SP-511.

Kottmeier, C., J. Olf, W. Frieden and R. Roth. 1992. Wind forcing and ice motion in the Weddell Sea region. J. Geophys. Res., 97 (20), 20,373-20,383.

Martinson, D. G. and C. Wamser. 1990. Ice drift and momentum exchange in winter Antarctic pack ice. f. Geophys. Res., 95 (C2), 1741-1755.

Simmonds, 1. 1985. Analysis of the "spinup" of a general circulation model. f. Geophys. Res., 90 D3), 5637-5660.

Simmonds, I. and W.F. Budd. 1990. A simple parameterization of ice leads in a general circulation model, and the sensitivity of climate to change in Antarctic ice concentration. Ann. Glaciol, 14, $266-269$.

Simmonds, I. and W.F. Budd. 1991. Sensitivity of the Southern Hemisphere circulation to leads in the Antarctic pack ice. Q. J. R. Meteorol. Soc., $117(501), 1003-1024$.

Worby, A. P., W. F. Weeks, M. O. Jeffries, K. Morris and R. Jaña. 1994. Late winter sea-ice-thickness and snow-thickness distributions in the Bellingshausen and Amundsen Seas. Antarct. 7. L.S., 29 (1), 13-15.

Worby, A. P., N. L. Bindoff, V. I. Lvtle, I. Allison and R. A. Massom. 1996. Winter ocean/sea ice interactions in the East Antarctic pack ice. EOS, $77(46), 453,456-457$.

Wu, X. 1993. A global sea ice model and its use in climate studies. (Ph.D. thesis, University of Melbourne.

Wu, X., I. Simmonds and W. F. Budd. 1996. Comparison of sea ice simulations with interactive and monthly-averaged-forcing models, J. Geoplys. Res., 101 D5), 93599374.

Wu, X., I. Simmonds and W. F. Budd. 1997. Modeling of Antarctic sea ice in a general circulation model. J. Climate, 10 4, 593-609.

Zwally, H. J., J. C. Comiso, C. L. Parkinson, W.J. Campbell, F. D. Carsey and P. Gloersen. 1983. Antarctic sea ice, 1973-1976: salellite passive-microwave observations. Washington, DC, National Acronautics and Space Administration. NASA SP-459. 